\title{
Presupposing, Believing, Having Faith
}

\section{Carlos Miguel Gómez Rincón ${ }^{1}$}

Published online: 8 November 2019

(C) The Author(s) 2019

\begin{abstract}
This paper traces the borders between presupposing, believing, and having faith. These three attitudes are often equated and confused in the contemporary image of the historically and culturally situated character of rationality. This confusion is problematic because, on the one hand, it prevents us from fully appreciating the way in which this image of rationality points towards a dissolving of the opposition between faith and reason; on the other hand, it leads to forms of fideism. After bringing this differentiation into sharper focus, a concept of faith in turn will come into view which challenges contemporary forms of fideism, to the extent that it embraces the possibility of examining and evaluating our systems of beliefs and basic presuppositions. This examination has nothing to do with justification or verification but rather with a sort of confrontation and discernment of the trust we have in what we take for granted.
\end{abstract}

Keywords Background presuppositions · Fideism · Hermeneutic rationality · Transcendence

The recognition of the historical and situated character of all our cognitive operations and actions constitutes a prominent philosophical development that since the end of the nineteenth century has been underway, particularly in the hermeneutic tradition with important echoes in some sectors of analytic philosophy. In fact, this insight has come to belong to our contemporary self-understanding: we conceive ourselves as historical beings, belonging to particular cultures and traditions from which we see the world. Moreover, this awareness of the situated and perspectival character of all our epistemic practices, value systems and forms of life, challenged and helped to transform the Enlightenment's image of rationality. According to this image, rationality would be a religiously neutral and self-sufficient method for checking and evaluating beliefs independent from all parochial commitment to any particular

Carlos Miguel Gómez Rincón

carlos.gomezr@urosario.edu.co

1 Escuela de Ciencias Humanas, Universidad del Rosario, Carrera 6 No. 12c-13, 00000 Bogotá, Colombia 
tradition, and to this extent would serve as warrant for an epistemic security beyond prejudice and authority.

Historical consciousness has contributed to the generation of a different picture of knowing, thinking, and acting, according to which we need to start always from a pregiven horizon informing our interpretation of the world, a horizon wich embraces culturally and historically changing practices giving shape to our research aims, procedures, and results. According to this new picture, the background of foreunderstanding is neither provided by rational investigation nor capable of rational justification or grounding but comes from different, non-theoretical sources. We simply take it for granted as the tacit framework which endows all our further intellectual operations and activities with meaning.

Even though this image of hermeneutic rationality is not universally accepted in contemporary philosophy, it offers an interesting possibility for rethinking the relationships between faith and rationality, which since the Enlightenment have tended to be exclusively captured under the narrative of a fundamental conflict. However, this possibility has also been obscured by confusion over the notions of presupposing, believing, and having faith. Thus, for example, Norman Malcolm claims that

religion is groundless; and so is chemistry. Within each of these two systems of thought and action there is controversy and argument. Within each there are advances and recessions of insight into the secrets of nature or the spiritual condition of humankind and the demands of the Creator, Savior, Judge, Source. Within the framework of each system there is criticism, explanation, justification. But we should not expect that there might be some sort of rational justification of the framework itself. (1992, p. 98)

According to Malcolm, something at least analogous to religious faith takes place in all forms of research and is constitutive of every thought system. We need to believe before we can think and know, and even though argumentation occupies an important place within each system, no rational justification can be given that transcends local frameworks of normative principles and interpretative values. All we can do, according to this view, is either to convert from one horizon to the next or to undo and rewrite the world we live in, a world suspended in the void.

Of course, this describes only one tendency of contemporary thought, which has also seen the defence and reconfiguration of robust forms of realism, as well as the attempt to overcome relativism even where the historicity of rationality has been accepted (Gómez Rincon 2017). However, my overriding concern here is with the exploration of this contemporary form of fideism, trying both to rescue its potential contributions to the understanding of the relation between religious faith and rationality, and to set its limits.

In the first part of this paper, I will attempt to explore the main characteristics of the background of fore-understanding that provides the conditions of ineligibility and the regulative principles of our thinking and action. On this basis, in the second part, I will try to differentiate the attitudes of presupposing, believing, and having faith, which are interwoven and confused in the contemporary image of rationality that exposes our condition as fiducial finite beings. Then, in the final part, I will suggest that religious faith requires and makes possible a questioning of what is presupposed and believed. 
This, I will claim, challenges contemporary forms of fideism making it possible to examine and evaluate our systems of basic presuppositions in a way that has nothing to do with justification or verification, but rather with a sort of confrontation and discernment of the trust we have in what we take for granted.

\section{Background}

If there have been discoveries in philosophy, one that would most surely deserve that name would be that of "the tacit dimension" (Polanyi 2009) within different streams of twentieth-century philosophy. Access to this dimension requires us to make a difficult distinction between two levels or strata in our thought and action: on the one hand, there is the level traditionally studied by philosophy, of propositional language and knowledge then there is a deeper, more basic, "foundational" in a sui generis way, presuppositional level composed of that which is simply taken for granted in all we say, think and do. The latter is nowadays commonly known as the "background" (Searle 1995, 127ss; Taylor 1993), and it is the puzzling characteristics of its "presupposed" character which makes the distinction between the two levels so difficult.

To utter any proposition, regardless of its illocutionary force, as well as to perform any intentional action, we implicitly assume a great deal of things about the world and ourselves which simply are not (and maybe cannot be) meaningfully expressed as part of that speech act or action, simply because such expression would have no purpose. And yet our sentences and actions would lack all meaning if these tacit assumptions were not made. We are not simply talking here about the contextual nature of all communication and understanding, according to which each particular communicative situation determines in large part the meaning of our utterances. Certainly, the particular place and scenario in which someone says, for example, "I will take a walk" and then leaves the room shutting the door, makes us understand not only the possible landscape she may find on her way but also to some extent her mood and the relationship between the conversation partners. But beyond this context, the whole situation implies a tacit understanding and a very particular sort of fiducial attitude that may be expressed to an extent in sentences such as "There are other human beings", "There will be a moment of time after this one", "I have a legged-body", "The door is a material object such that it can be shut", and "The world has certain characteristics that allow me to walk" (because we simply have no need to accompany our actions with them). How can we characterize these tacit understandings and fiducial attitudes, and why are they different from the things we simply say and do while presupposing them?

Interestingly, during the first half of the twentieth century, various philosophers, many times without contact among themselves, identified a group of more or less common features of the tacit dimension. I will attempt to systematize them here in a rather schematic way, which will not allow me to enter into the intricacies of each thinker's argument or the differences between them. My aim in this section is only to offer a characterization of the elements that constitute the background, with a particular focus on what its presupposed character means. 


\section{Non-propositional presuppositions}

The main difference between the two strata of our thought and action is the nonpropositional character of that which is presupposed. This formulation, common to most philosophers of the tacit dimension, is complex and requires careful examination. Let us start with the simplest way of presenting the issue, paraphrasing Collingwood's (2014, pp. 2133) renowned argument in favor of what he calls absolute presuppositions: All we affirm about the world with the purpose of describing it needs to be understood as the answer to a question. So, no descriptive or assertive utterance has meaning on its own, independently of the context of inquiry in which it is formulated. Now, these questions, on their part, already imply certain affirmations about the world. These are the presuppositions of the question and can be themselves answers to other questions. But if the analysis goes on inquiring about what is presupposed, we will find that certain presuppositions are not the answer to any question, but are simply there, as the ground that makes the whole inquiry possible and can be neither justified or verified, nor compose the object of any sort of empirical research. These Collingwood calls absolute presuppositions.

Take the following example. "This virus is the cause of that illness" is the answer to a question seeking causal explanation in medical research, which in turn presupposes many things about viruses and body functioning. One can ask questions for which these pieces of knowledge are a suitable answer, as well as require additional explanations, demonstrations, and proofs of their reliability. But if we keep pushing the inquiry, we will find that the whole enterprise of medical research is based on taken for granted assumptions regarding issues such as what a proper explanation is, what kind of things we are dealing with in this domain, how nature is uniform and events are causally linked in the world, and how natural processes can be made intelligible. A regular medical researcher never enquires about this constellation of presuppositions that guide and direct his work, but takes them for granted as the horizon in which his whole practice moves.

Now, even though these presuppositions can be expressed in a form that seems to be propositional, that is, as assertions about a particular aspect of reality whose truth or falsehood might be established by means of an appropriate process, part of their non-propositional character means that they do not constitute knowledge. ${ }^{1}$ One of the key arguments offered by the philosophers of the tacit dimension in this regard is that, unlike propositions, there is no way in which we can epistemically evaluate, prove, disprove or justify them, because in order to conduct a process of verification or justification, we already need to take them for granted. We simply see and study the world from them (Taylor 1993; Polanyi 2009, p. 10; 1975, p. 34), and our knowledge results from what they allow us to grasp.

Wittgenstein called them certainties that which "stands fast" for us (1969, sect. 116, sect. 152), as the soil, sediment, ground, or rock-bottom (OC sect. 97, sect. 98) of all our intellectual activities, which allow us to distinguish true from false (OC sect. 94, sect. 162) and nonetheless belong to a different category than knowledge (OC sect.

\footnotetext{
${ }^{1}$ Part of the difficulty to distinguishing the propositional from the non-propositional dimension lies in the fact that some of the philosophers that have attempted the distinction tend to use the same terms to refer to both levels. Thus, for example, while trying to point out their radical difference, Wittgenstein uses the term proposition (Satz) to refer both to the basic certainties (die Angeln) and to ordinary or factual propositions. But, in so doing he constantly points out that they play different roles and fulfill diverse functions, the former being grammatical rules for the latter (OC 35, 36, 37, 51, 57; Cf. Moyal-Sharrock 2004, 33ss). Likewise, Wittgenstein but above all Ortega uses the term "belief" to refer to the non-propositional.
} 
243, sect. 308). Neither do we arrive at them as a result of research (OC sect. 138, sect. 337; Ortega y Gasset 1977, p. 24), because they are that which our research methods presuppose; nor can experience prove or disprove them, because we interpret experience through them (OC sect. 130, sect. 145; Cf. Collingwood 2014, p. 194).

This first element of the non-propositional character of presuppositions clearly presupposes the traditional understanding of knowledge as justified true belief. It seems evident that Wittgenstein assumed this definition in his analyses in On Certainty (OC sect. 91; Moyal-Sharrock 2004, p. 15). But, given that truth and justification are not necessarily linked in this definition of knowledge, someone could object that absolute presuppositions could anyway be considered as being true, even though we could never prove it or know it. ${ }^{2}$ This, however, would not be enough to defend their propositional character. For this, it is not only necessary that a proposition refers to something, i.e., that it has a propositional object, but it is fundamental that in being asserted or affirmed, it raises a validity claim regarding the truth of its content, which necessarily generates a commitment to justification (Cf. Habermas 2003, p. 36). Of course, justification can be of many kinds and not exclusively empirical, depending on the argumentative framework in which the truth-claim occurs. As we will see, absolute presuppositions generate these frameworks determining the conditions of justification. For now, the point I want to make is that presuppositions cannot fulfill a propositional function insofar as justification does not apply to them. Their function, we are about to see, is different from offering a true description of certain aspect of the world.

This leads us to a second important sense in which these basic presuppositions are different from propositions. The former are never "asserted", "affirmed", or "propounded" (Collingwood 2014, p. 33; Ortega 1977, p. 25). To presuppose is not to affirm or to claim anything, which, as we just indicated raises a truth claim and generates a commitment to justification. What is it then? In order to refer to it, authors normally use the expression "to take for granted". This, however, should not be understood as the operation of assuming or granting, "for the sake of the argument", a certain idea or theory, in order to, for example, explore its implications, to see what follows from it or to use it as a means for further research. We can call these presuppositions basic or absolute insofar as we are not even aware of them, nor can we become aware of them without a special effort involving, say, confrontation with a different background or a careful reconstructive analysis. In Ortega's (1977, p. 23) words, "we do not have them but are in them", and "are them" (24). We necessarily have to "count on" them insofar as they "are our world and our being", and we take them for reality itself (24). That which is taken for granted is never thought; it simply lies there as the subsoil of our life (27), the "firm ground" on which all our activities take place (34).

A third fundamental feature that differentiates presuppositions from propositions is the different function they play in thought and action. While the latter are normally understood as making a statement about the world or ourselves the truth or falsehood of which could be justified, presuppositions do not refer directly to the world but rather establish what can be meaningfully talked about and done in the world. They

\footnotetext{
${ }^{2}$ For this and many other insightful comments and criticisms, I am deeply grateful to one of the blind referees of the previous versions of this paper. I have tried to respond to most of them the best I could, though surely not in an entirely satisfactory way for this critic.
} 
inaugurate the context of fore-understanding of the world, our Weltbild, the framework (Gerüst) of all our considerations (OC sect. 93, sect. 95; sect. 105). Accordingly, they have a regulative function in our thinking and action (OC sect. 87, sect. 167, sect. 211). This regulative function may involve different tasks, among which the following are commonly referred to in the literature: (a) they open up certain region of reality for research by determining the ontological characteristics and fundamental structures of the objects that constitute it and which are to be studied, providing thus the general terms for describing and explaining phenomena (Heidegger 2001 sect. 3; Kennick $1955,775 \mathrm{ss}$ ). For this reason, (b) "they determine the entire structure of [a particular] science by determining the questions that arise in it and therefore determining the possible answers" (Collingwood 2014, p. 52). (c) In this sense, absolute presuppositions do not represent reality but work as "organizing and interpretative notions which are not empirically given, but which transcend experience" (Nelson quoted by Kennick 776; Cf. Searle 1995, 133ff). Now, insofar as they operate non-propositionally, (d) they enable all intentional states, constituting abilities, capacities, and dispositions for coping with the world (Searle 1995, 129ff). Indeed, the background enables both linguistic and perceptual interpretation because, on the one hand, it provides the conditions of intelligibility that determine the literal meaning of particular sentences - since individual utterances do not carry these conditions as part of their content (Searle 1995, p. 130) - and on the other hand, make us "able to see things as certain sorts of things" (133).

Finally, probably the most interesting reason why absolute presuppositions differ from propositions is that they should be envisaged not so much as psychological or mental states or contents, rather as practical attitudes, dispositions, and ways of acting. Let us consider this aspect in some detail.

\section{Enacted interpretations}

Presupposing, in the sense, we are exploring here, implies acting with an absolute trust in something which can be expressed as a result of reconstructive analysis but is not affirmed or represented in the mind while the action is performed. Part of the reason why that in which we implicitly trust is never said is because such a sentence would simply lack any use in our normal communicative practices (Phillips 18). We never accompany an action such as passing the salt on the table with expressions such as "and this is a material object", "and you are a human being", and "this is an intentional action". In the context of that particular action, these expressions lack any meaning because they do not have any use, that is, they play no communicative role or function (Moyal-Sharrock 2004, pp. 43, 94). Thus, to be presupposed is just to go without saying, because, as we have said, basic presuppositions establish the horizon of understanding in terms of which any sentence is produced and any action is performed. Nevertheless, this horizon, rather than constituting a mental picture, comes into force in our ways of acting and being in the world. As Phillips indicates, the point is not that we behave as we do because of our world-picture, but rather that "acting as we do is our world-picture" (24).

This means, on the first place, that there is something primitive, instinctive-like, "animal" to it (OC sect. 359, sect. 475). This does not need to be interpreted in the sense of presuppositions being some sort of innate behaviors or remains of ancient evolutionary 
stages still present in us, but rather as the immediate, though meaningful responses and ways of acting proper to purposive activities. It rather implies an inversion of the relationship between thinking and acting. On the one hand, purposive, intentional action does not require us to have a directing idea or representation of the goals of action "in mind", before or while it is performed. To be a master of a practice means just this, think of a football player who skilfully responds with a particular movement to score a goal without being explicitly aware of a game strategy or plan. Certainly, his practice is a highly sophisticated and culturally specific way of doing things, in which we act "automatically" though meaningfully. In this connection and building on the whole idea of the background, Hubert Dreyfus and Charles Taylor have recently recovered from Merleau-Ponty the concept of "motor intentionality": "skillful coping does not require any representation of a goal. It can be purposive without the agent entertaining a purpose" (Dreyfus and Charles 2015, 48ff).

Accordingly, on the other hand, the instinctive-like character of presupposing has to do with the fact that certain practices underlie as the "ground" and establish the end of all justification processes. In Wittgenstein's words, "it is our acting, which lies at the bottom of the language-game" (OC sect. 204, cf. sect. 110, sect. 509). But, we have just suggested, a way of acting should be understood here as taking part in a highly codified, meaningful activity. As part of a way of life, it forms a pattern of goal-oriented and skillful ways of coping with reality made up of practices which are, of course, always culturally centred. For this reason, presuppositions are not only expressed but mainly embodied in practices, constituting en-acted interpretations (Moyal-Sharrock 2004, p. 97). Thus, Wittgenstein's affirmation that, "At the foundation of well-founded belief lies the belief that is not founded" (unbegründete Glaube) (OC sect. 253) can be interpreted as a recognition that even though all justificatory processes have a limit in something that cannot be justified, this bottom rock is not merely irrational or beyond meaning. For practices are already patterns of meaning belonging to a particular form of life.

The first division of Martin Heidegger's Being and Time is dedicated to the exploration of this astonishing feature of the background. In so doing, this influential book has contributed as no other to transforming the image of knowledge, rationality, and humanity that prevailed in Western thought for centuries. Our primordial and original relationship with the world is not theoretical contemplation or disengaged representation but indwelling; that is, being occupied in (besorgen) or concerned with (Macquarrie and Robinson 2001, p. 83) many purposive activities in which we discover entities as instruments or "equipment" - as the German term Zeug is translated in the English edition (Macquarrie and Robinson 2001, p. 97; Cf. Dreyfus 1995, 61ss), related to each other in ways that establish networks of meaning (Heidegger 2001, sect. 15). Now, these original meanings are previous to propositional formulation and make it possible (SZ sect. 33). They are ways of understanding (verstehen) the world that are embodied in our ways of coping with it (SZ sect. 31). Theory aries only after our basic practices are interrupted, and we have to attend to the instruments we use and the objects we encounter not anymore for the sake of that which we do with them, that is, as part of our engaged dealing with the world, but as having certain properties and characteristics which were only known-by-using them during the practice (SZ sect. 13). Only then does our know-how becomes a know-that.

We cannot help completely trusting in these pre-conceptual interpretations of the world because they establish the conditions of possibility of the practices in which we are constantly engaged. Without this trust, no meaningful action would be possible. 
They are rightly called interpretations because things appear in them from the vantage point of the goals of the practice. They are the means through which we are in contact with the world; we discover its different aspects and modes of being from the perspectives that our interested activities allow. In this sense, a background offers the fundamental horizon of meaning within which perceiving, experiencing, saying, and doing certain things in the world become possible.

\section{Non-foundationalist foundations}

The philosophers who have analysed background presuppositions have used metaphors to describe them as the basic grounds and foundations of a system. In which sense are they so? The first thing to note is that they do not serve as the classical foundations for foundationalist epistemologies. This for various reasons. Given that they are not propositions, they do not relate inferentially to that which they ground. (Cf. Collingwood 2014, p. 67). That which rests on them cannot be inferred or logically derived from them because they have no justificatory power. Rather, they are the conditions of intelligibility of propositions, and as indicated before, they play a regulative function. Hence, to be grounded on them is very different from being justified by them, and thus, they cannot be the basis of the entire epistemic building.

What is then the relationship between fundamental presuppositions and that which rests on them? We listed above some of the directive and regulative functions they have in thinking and action. Background presuppositions are the taken for granted, enacted interpretative and regulative "principles" that open up a world to be investigated, lived, and acted upon. A foundation, in this sense, is not an epistemic ground, but a founding way of seeing and acting in the world. It inaugurates and establishes a horizon of lived meaning that makes our thinking, experience, and action possible.

In an extensively discussed chapter, Avrum Stroll argued that Wittgenstein's certainties should be regarded as the foundations for a non-conventional type of foundationalism. By this, he understood a very general model, shared by all foundationalist theories, according to which there are two strata in knowledge, one which is more fundamental or basic than the other. Classically, both strata are of the same nature, in that both are propositional and thus are pieces of knowledge, related in such a way that the most basic level warrants the other, which therefore depends on it (Stroll 1994, 143ss). According to Stroll, Wittgenstein's originality would be to have challenged this view, by showing that the fundamental level is neither true, nor false (i.e., either non-propositional or constituted by a sui generis type of propositions), but, nonetheless, it is certain (155). And, since certainty, as we have been exploring, is a mode of acting proper to our being immersed in cultural practices,

Wittgenstein's genius consisted in constructing an account of human knowledge whose foundations, whose supporting presuppositions, were in no ways like knowledge. Knowledge belongs to the language game, and certitude does not. The base and the mansion resting on it are completely different. (145)

It is uncertain whether we can continue to call this position foundationalism. What is the point of having foundations that do not warrant our knowledge claims? Clearly, the 
notion of "foundation" must be reformulated in a way that deeply transforms our image of rationality. I cannot enter into the whole discussion surronding Wittgenstein's alleged foundationalism here. (Cf. Cardona 2011; Moyal-Sharrock 2004, p. 77) Rather, I would simply like to highlight one of the reasons that have been given for the rejection of Stroll's interpretation, in order to include it in my account of enacted presuppositions. It has to do with the holism of primitive certainties. The presuppositions we are exploring form systems (OC sect. 105, sect. 141; Ortega 1997, p. 31) or constellations (Collingwood 2014, p. 66) with no linear relationship among them or with that which rests on them. No necessary connection links them, so "a person supposing any one of them is [not] logically committed to supposing all or indeed any of the others" (Collingwood 2014, 67). Accordingly, it is not possible to infer that someone presupposes something because he takes for granted some other thing. The holistic character of the background consists, then, of non-inferential relationships between its elements. In this sort of system "some things stand unshakeably fast and some are more or less liable to shift. What stands fast does so, not because it is intrinsically obvious or convincing; it is rather held fast by what lies around it." (OC sect. 144, cf. sect. 152, sect. 248)

\section{Absolute but historical}

One last and essential feature of background presuppositions, which has also given rise to much discussion, is the tension between their status as absolute certainties within a system embodied in practice, and their changing character as historical entities. Indeed, human historicity is synonymous with our living within traditions (Gadamer 1990, $277 \mathrm{ss}$ ), which are what the constellations or systems of presuppositions constitute. That is why both Ortega and Collingwood considered their study as the main object of historical science. While for the former the subsoil of a historical period is constituted by what he calls "basic beliefs" (1997, pp. 23-28), the latter considers absolute presuppositions as a particular class of historical facts $(2014$, p. 62), because the constellations they form establish a historical "phase". What does historicity add to our description of fundamental presuppositions?

In the first place, the historicity of presuppositions means that they are in permanent transformation. This may seem to preclude the possibility that they may also be absolute. This is not the case, however, because to be absolute means that they are the regulative, non-justifiable, and unquestionable enacted principles of a background; or to put it differently, they are absolute only internally, that is, with reference to the particular horizon of understanding they constitute. But backgrounds are subject to transformation. Indeed, as Collingwood suggests,

The essential thing about historical 'phases' is that each of them gives place to another; not because one is violently destroyed by alien forces impinging on its fabric from without by war or from within by revolution, but because each of them while it lives is working at turning itself into the next. $(2014,73)$

This means, secondly, that a constellation of basic presuppositions is not a static, tensionless system. There are always internal tensions and strains (Collingwood 
2014 , p. 74) that make them dynamic systems. We cannot analyse here how these tensions are produced and how background transformation works, but can only indicate that this internal dynamic of constellations implies a change of function between the presuppositional and the propositional level of thought and action. In Wittgenstein's words:

It might be imagined that some propositions, of the form of empirical propositions, were hardened and functioned as channels for such empirical propositions as [they] were not hardened but fluid; and that this relation altered with time, in that fluid propositions hardened, and hard ones became fluid (OC \$96).

In this sense, the absolute character of a presupposition derives from its function within a system, and the functions may change: empirical propositions may become presuppositions and vice versa. "The same proposition may get treated at one time as something to test by experience, at another as a rule of testing." (OC sect. 98, cf. sect. 167, sect. 211) Now, this change of function requires, at least to some degree, our active participation in the process of reconfiguring the traditions in which we live. This is the third characteristic of the historicity of the background. We are neither encapsulated in a unique, incommensurable system, so that we cannot learn a different form of life; nor are backgrounds closed systems that cannot be expanded. The word "horizon" is very suggestive of the sense of fundamental openness of backgrounds: they move while we move, allowing us to see new aspects and indeed new things (Gadamer 1990, 310ss/ 2004, 302ss). What is more, "To acquire a horizon means that one learns to look beyond what is close at hand-not in order to look away from it but to see it better, within a larger whole and in truer proportion" (Gadamer 2004, p. 304).

\section{Clarifying the spectrum}

The analogy between the attitude towards foundational presuppositions and religious faith has been pointed out in similar terms by philosophers of the tacit dimension. According to Collingwood (2014, p. 46), for example, absolute presuppositions "give people more than a touch of the feeling which Rudolf Otto called numinous terror". Indeed, "the result of simply presupposing our presuppositions, clinging to them by a sheer act of faith ( . . ) is the creation of religion" (197). Even more, for him "That God exists is not a proposition, it is a presupposition" (188). Similarly, for Wittgenstein "The propositions describing this world-picture might be part of a kind of mythology" (OC 95). And according to D.Z. Phillips, religious beliefs are "absolutes for believers in so far as they predominate in and determine much of their thinking. The absolute beliefs are the criteria, not the object of assessment." (Phillips 1993, p. 65)

As already pointed out, this analogy between religious faith and the primitive certainty of absolute presuppositions has contributed to transforming the Enlightenment's image of rationality and knowledge. Every rational activity and justificatory procedure rests on something that cannot be justified but is simply taken for granted. Basic trust is prior to propositional activity and determines it. However, religious faith cannot simply be equated with presupposing, just as it cannot be reduced to believing. Indeed, the analogy hides a lack of precision that needs to be sorted out. One of the 
main difficulties involved in adequately differentiating these three attitudes is that they seem to constitute a continuum. Their proximity makes their boundaries diffuse and sometimes one can either lead to another, or be accompanied by it. I would like now to explore the borders between these three attitudes or groups of attitudes. I will begin by investigating the limits between presupposing and believing.

\section{Taking for granted as a form of primitive certainty}

The first difference between these two attitudes is related to the fact that, as we saw above, to presuppose means to take for granted in a non-propositional way; that is, not assuming that a proposition is certain, but simply to live and act on the basis of certainty that, even though it can be linguistically reconstructed and articulated through analysis, is primarily expressed and contained in what we do and say. The sureness proper to taking for granted, as Phillips (2005, p. 23) puts it, "is not the presupposition of our ways of thinking and acting, but a sureness found in our ways of thinking and acting."

On the contrary, belief can be either a propositional attitude, as it has been typically defined, such as affirming or maintaining a proposition (believe-that); or it can also be a form of trust in a person or situation (believe-in) ${ }^{3}$. In both cases, believing involves different grades of security. I can completely trust in a person, or be more or less sure about "this and that being the case". Presupposing, on the level we have been elucidating here, admits no grades of security. It is rather a form of basic, primitive certainty (Mulligan 2006). This means that it is absolute in the sense that it is not even possible to doubt it. This is so, as Wittgenstein has shown, because doubting a basic certainty is simply logically impossible: it would require us to abandon the horizon of meaning in which one is located and from which it is possible to ask any questions, perform any activity and even make mistakes (OC sect. 72, sect. 195). Indeed, the exercise of doubt requires that we take for granted a whole constellation of presuppositions in order to have and formulate any doubt. It is only from the horizon of taken for granted presuppositions that doubt can emerge (OC sect. 115, sect. 341, sect. 519). Beliefs, on the contrary, can be questioned, put into trial, confirmed or abandoned without altering the background.

Secondly, even though the biggest difference between presupposing and believing is related to belief-that, belief-in is evaluative and affective in a way that presupposing is not. Because trusting in someone or something, such as an idea or a theory, implies regarding her or it as good, worthwhile, trustworthy and the like (Moyal-Sharrock 2004, 189ss). Tacit trust, on the contrary, does not require such an evaluation and emotional commitment. Finding out that, for example, objects disappear when I do not look at them would be literally mind-blowing, but it would not be felt as a disillusionment or betrayal.

Another important difference between presupposing and believing has to do with their relation to reason and justification. While, as we have said, a foundational

\footnotetext{
${ }^{3}$ There are other relevant modes of believing that we are not considering here. Among them, "believe someone" and "believe someone or something to be X" (Mulligan 2006; Moyal-Sharrock 2004, p. 188). For our discussion, it is enough to differentiate propositional believing (believing that) and non-propositional believing (believing in) from presupposing and having faith.
} 
presupposition is neither the result of reasoning, nor relates inferentially to that for which it serves as a condition of intelligibility, both kinds of belief (belief in and belief that) rest on grounds and are affected if these grounds are shaken. This is why belief constitutes knowledge. A belief is always part of a reasoning and interpretative process that confers upon it a varying degree of security. We are entirely entitled to demand for the reasons or grounds of a belief, and thus to judge them as appropriate, sufficient, or inadequate; we can also develop different theories of what constitutes a good ground for certain types of belief; and all these efforts contribute to the maintenance or the abandonment of a belief. Likewise, our trust in someone may be more or less justified by our previous experiences with that person, our knowledge about her, etc. (Cf. Audi 2011, p. 66). But justification does not apply to foundational presuppositions, as we have shown, and therefore our basic certainty is immune to justificatory reasoning. To change them is to convert from one worldview to another. (OC sect. 92)

Finally, the kind of attitude that primitive certainty entails is very different from the two types of attitudes proper to belief. It is primitive not in the sense of being historically or evolutionary prior to more developed kinds of attitude (such as propositional belief), but rather because it is, as explained before, somehow an automatic or instinctive reaction, even though it is expressed in the most sophisticated practices and activities (Cf. Moyal-Sharrock 2004, 192ss). When we have mastered a practice, we simply do things without thinking about what we are doing, though our actions remain highly intentional, as in the case of the jazz musician or the football player we considered above. Quite to the contrary, both belief-that and belief-in require having in mind that which is believed and trusted, as well as why one should believe so.

\section{Religious faith as expectant openness}

Let us explore now the border between presupposing and having faith. In the first place, even though religious faith, like presupposing, is a kind of non-propositional attitude related to trust, it is so for different reasons. On the one hand, faith is not the affirmation of any proposition simply because reference functions differently in religious language than in ordinary or descriptive language. The divine is not an object among the other objects of the world that could be fully described, represented or apprehended in concepts and words. Its transcendence (sometimes even linked to ineffability) is commonly recognized in most religious traditions. This is the reason why symbols and metaphors are the privileged vehicles of religious language, which points towards the transcendent, aiming to generate an attitude and to promote a certain form of life, instead of attempting to fully describe it. Thus, even if faith may be accompanied and allows for the formation of propositional beliefs, it cannot be reduced to them.

Also for this reason, while in presupposing, we get in touch with the rock-bottom, the soil, the ground of the background, faith is a relationship with that which transcends all backgrounds since it can never be fully conceptualized or said. Otherwise put, in faith we encounter that which, transcending all backgrounds, bursts into them. The divine can never be reduced to or fully expressed in the terms of any background, even though all our religious symbols, practices, and beliefs are always historical attempts to refer to it and to direct our lives towards it. Faith is the attitude in which we attempt to live our lives with this orientation. 
Secondly, the act of having faith is explicit. This brings it close to belief-in and far away from presupposing. The basic trust we have in what we take for granted completely diverges from the trust in God proper to theism. This for different reasons. Even though faith is shown and expressed in actions, it is not simply embodied in them. It requires a sort of self-awareness and voluntary acting and living towards Him in whom we have faith. What does this living towards mean? It is not a primitive trust, which is, as we saw, non-evaluative, but on the contrary, a kind of trusting hope, which requires, similarly to believing-in, the highest appreciation of that which in which we place our trust. Consequently, religious faith and trust cannot be equated. Not every form of trust is a form of faith. For you can trust in things that you do not hold in your highest esteem or regard as supremely valuable, meaningful, benevolent, and the like, as when you trust, you will soon find your wallet or pass an exam (Cf. Audi 2011, p. 71).

Additionally, in order to work properly, absolute presuppositions must remain nonthematized, to the point that to question them has no meaning or can only be done when new presuppositions have appeared. In this sense, the security they offer is of that which cannot be questioned, a security typical of common sense. Faith in God, on the contrary, is never secured in this sense of appearing to be natural or being taken for granted, even for the religious person. Faith can be lost or weakened; it can fail. (Lk 22: 32) Thus, faith implies a tension and a response. Neither can it be produced by means of argument, nor can it be unproblematically transmitted through direct socialization as presuppositions are transmitted when learning a practice. Religious faith requires the experience of encountering the divine, active and present, never fully cognizable and not objectifiable. Since this encounter does not depend on the will, nor is it simply present in ordinary experience, it is considered both a goal and a gift. Instead of taking for granted certain interpretations of the world, faith is a kind of disposition and relationship that need to be nourished. Thus, it is both an invitation and a task.

Thirdly, our trust in absolute presuppositions depends on the system they constitute and is warranted by the inner needs of a thought system. Religious faith, on the contrary, depends, at least in theistic experience, on the manifestation of Him in whom all trust can be placed. Only because God reveals himself can we trust in him. But revelation is never completely unambiguous, insofar as each revelatory event, can be interpreted both theistically and naturalistically. In this sense, faith is not an affirmation that certain facts occurred or that things are in a certain way, but rather a way of seeing things as revealing or expressing something that comes from beyond them, for example a deeper meaning or purpose, or the presence or sign of bliss, grace, or love. But the same things and events can also be interpreted in a naturalistic sense because reality is religiously ambiguous (Hick 2004, p. 12). The "wonders of nature", or certain historical events, for example, can be read both as signs of the divine or as merely contingent and purposeless happenings. For this reason, faith can never be the product or the result of an argument (Cf. Malcolm 1992, p. 102). Seeing certain facts as either a proof for or against, for example, God's existence, already depends on whether you are a person of religious faith or not.

Christian experience is emblematic here. Even the Incarnation, which is considered in Christianity to be the moment in which God manifests himself to the fullest, incites much controversy and commotion (I Co 1: 18-25). Not even this event is transparent for those before whom Jesus acts. The Gospels abound in confrontations on this regard. 
For many, neither the testimony of Jesus's miracles nor the interpretations of Scriptures, reputable sources of authority in that time, offer enough evidence in favor of Jesus being the Messiah. Seeing is not enough to ensure faith. Jesus claims that he has come so that those "who do not see may see, and those who see may become blind" (Jn 9: 39). How is it possible to see in different ways that which presents itself to all? Even though revelation is necessary for religious faith, it is not sufficient. The additional element, on the part of the person of faith, may be grasped through appeal to the metaphor of the call and the response (Gen 12: 1-6; Jn 10: 3), a dynamic which inherently involves interpersonal relationships. Listening and following are commonly associated in the biblical tradition with faith.

Accordingly, having faith differs both from affirming the truth of a certain doctrine and from taking for granted a metaphysical presupposition. Indeed, it is possible to have faith without forming any belief-that; or as Audi (2011, p. 53) has pointed out, religious faith is not necessarily doxastic, "just as one can have faith that a friend will survive cancer, without either believing or disbelieving this". This does not mean that faith excludes belief (propositional or fiducial), but that they can occur with a certain level of independence; and in any case, having faith does not require believing a great deal of things. Moreover, to have faith in something (i.e., my friend will recover from cancer) may even be compatible with harbouring doubts about it (Audi 2011, p. 76). All this shows that faith and belief are different attitudes, and as a consequence, faith can never be thought of as "believing without evidence" or "believing on inadequate evidence", as modern sensitivities have encouraged some to suggest.

Also for this reason, faith differs from dogmatism. It is possible to affirm many doctrinaire propositions based, for instance, on the confidence in a certain type of religious authority, but that does not imply or require having religious faith. You can even believe that, for example, "God exists", without having faith in God; that is, without striving to live your life in a relationship of reverential trusting hope towards God that generates certain feelings, attitudes, dispositions, and actions towards your fellow human beings and the rest of creation. Surely, the trusting hope you have in God may express and even imply your belief that God is merciful, loving, and good; but such belief does not commit you to a particular definition or theory about what those words mean when applied to God. Rather, your faith in God is an experience that opens you to something for which those adjectives are mere indications, and indeed faith requires that you are aware of how pale, insufficient, and improper they are.

This openness proper to religious faith runs even deeper. Here we find a final difference between presupposing and having faith, one which has the potential for reestablishing the sense of the divine in our contemporary predicament. "My life - says Wittgenstein towards the middle of On Certainty - consists in my being content to accept many things" (OC sect. 344). This kind of basic acceptance (zufrieden geben) is the condition for the emergence of any form of dissatisfaction, as certainty is the basis for doubt. Primitive trust is our most fundamental way of being in the world. But the non-epistemic nature of fundamental presuppositions, which makes doubt logically impossible at the level of framework presuppositions, as well as making the demand for justification of a background absurd, does not make the background invulnerable to change, transformation, and eventual abandonment. As we pointed out before, this is at least part of what the historical character of background presuppositions means. That which lies as solid rock at the bottom may become fluid, and the propositions we assert 
based on that soil can harden (OC sect. 96). So, our life consists in our taking for granted in our ways of acting and thinking a worldview that, even though it cannot be further justified, will change and even in large part eventually disappear. In this sense, our basic trust is a non-propositional certainty in action (in der Tat), but the patterns within which our actions are integrated and from which they receive their meaning, that is to say our practices, only stand fast insofar as the whole system endures. The "foundation-walls are carried by the whole house" (OC sect. 248), but the house is bound to be demolished and rebuilt.

One of the greatest poets of the tacit dimension, Rainer Maria Rilke, was able to grasp the risk and fragility in which this contemporary awareness sets us:

And even the animals sense very quickly

that we are not fully secure, not really at home

in the interpreted world. (Duineser Elegien, Erste Elegie,

Trans. Cottingham 2003, 78)

The "discovery" of the tacit dimension generates a double awareness constitutive of our contemporary self-understanding: we live in a background and it will not last. Thus, anguish is the other side of primitive trust. We are never at home in our interpreted worlds. Once the tacit dimension has been discovered, once its awareness belongs to our self-understanding, primitive trust is accompanied by a fundamental uneasiness. This, of course, does not occur in action, so we can continue to be engaged in our practices. Rather, this uneasiness is a sort of global feeling that things might have been otherwise, and that there is a fundamental inadequacy in our forms of life and ways of acting and thinking. The experience of faith, in which that which transcends all backgrounds streams in to meet us, permanently reminds us of this. All immanence is bound to dissolve. Here again faith is a way of seeing this radical impermanence as a sign of the presence of the divine, instead of as a motive for lamentation and despair; it is the recognition of transcendence in all that stands fast. Again in Rilke's words:

Thou art so immense, that I soon become nothing,

when I just close to thou am.

Thou art so dark; my small clarity

has no meaning by thy edge.

Thy will moves like a wave

and each day in it sinks. (2008, Erstes Buch)

Paradoxically as it may sound, faith challenges fideism. This is, in line with our analysis of absolute presuppositions, the claim that we are always confined to one or another background that we can not evaluate, and that our attitude towards presuppositions is closely related to religious faith. Although justification, within each background, finds its end and soil in the enacted presuppositions that constitute a horizon of fore-understanding, and there may be no way to further justify whole backgrounds, they nonetheless are fundamentally open and dynamic. Insofar as faith is a way of taking on and living this openness as a permanent movement towards transcendence, in the light of faith all taken for granted presuppositions and well-established beliefs 
appear evanescent. Radical scepticism is however not the consequence of faith. Since faith is a way of seeing and encountering in everything a sign of Him towards whom we are moving, the movement becomes an expectant openness. There is no openness wider than that effectuated by faith.

\section{The confrontation of trust}

If the expectant openness proper to faith has this potential of challenging fideism, then it may be possible that faith can also help us to examine the horizons of foreunderstanding in which we live. This form of examination has nothing to do with justification or verification. Rather, I would like to suggest that faith makes it possible a kind of confrontation or discernment of our absolute presuppositions, which leads to a revision of our fundamental commitments. What kind of confrontation would this be? I want to finish this article by proposing some key elements that need further reflexion.

To begin with, the confrontation of our beliefs and certainties that faith makes possible would bring about the recognition and the acceptance of our predicament as fiducial beings. This would prevent us from irrevocably opposing faith and rationality. Simultaneously, it would attenuate the dogmatism proper to certain forms of believing that aim to exhaust the totality of what can be legitimately known and experienced. Pascal claimed that "every religion which does not affirm that God is hidden, is not true; and every religion which does not give the reason for it, is not instructive" (1909, VIII, 585). Paraphrasing him, in our present situation, we could affirm that every belief system that does not incorporate the awareness that reality cannot be exhausted in its concepts is inappropriate, and every system that does not explain how it points or directs us towards reality is superfluous. In this sense, the confrontation of belief systems made possible by faith gives rise to epistemic humility.

Humility, however, has nothing to do with agnosticism or scepticism. On the contrary, at the level of basic certainties, the confrontation proper to faith makes it possible to thematize and articulate the primitive trust implicit in them. This shifts the focus from the issue of justification to that of clarification of our fundamental presuppositions. If it is not possible to think or to act without taking something for granted, then the question regarding the fundamental commitments that make my thinking and acting possible, must be constantly formulated. Clearly, the aim of this questioning cannot be the thorough clarification of the whole constellation of absolute presuppositions of one's particular horizon of fore-understanding, which would eventually lead to the absolute transparency of thought. This simply cannot be done, since every clarification attempt already presupposes a horizon of fore-understanding which remains unthematized (Cf. Taylor 1993, p. 328). Rather, articulation of tacit commitments is a gradual and generally local process oriented towards the interrogation of these commitments. This is indeed one of the basic tasks of philosophy, but faith allows for a particular form of critical clarification that might be formulated with the question: Is that in which we tacitly trust compatible with the need we have to trust it?

We saw that any justification process depends on absolute presuppositions, which remain exempt from justification. We need to take for granted one or another constellation of such presuppositions, acting on the basis of a tacit fundamental trust. This trust, however, can be articulated and interrogated by confronting it with religious faith, 
asking whether that in which we trust, so to speak, deserves our trust. This is not a personification of presuppositions. Rather, the point is to inquire whether what we take for granted is so (or is tacitly interpreted in such a way) that it can really make the cognitive operations and activities that we perform based on that trust possible, and in a way that leads to the results we expect from them. If, for example, that which works as the absolute presupposition of a worldview is such that it makes the epistemic reliability of the very cognitive operations that give rise to that worldview impossible or unreliable, then we find ourselves confronted with a performative contradiction. (Cf. Clouser 2013, pp. 84-87)

In order to better understand the examination of tacit trust introduced by faith, we can reformulate the question in these terms: what kind of absolute presuppositions cancel the trust we necessarily must place in them? The case of self-referential inconsistent principles comes here to mind. But beyond them, faith, at least in the theistic sense, makes it possible to examine primitive trust in so far as it opens all backgrounds towards Him who being transcendent can be the sole locus of absolute trust. Differently said, theistic faith works as a contrast medium against which fideism can be reconsidered. In between the cracks of presuppositional trust, faith introduces the opening towards transcendental trust.

Now, the "compatibility" between the nature of that which is presupposed and the fact that we need to hold trust in it while engaged in our thinking and acting, has more than a logical sense. This compatibility is related to truth, not in the sense of correspondence between presuppositions and the world or in the sense of the commitment with justification of the validity claim raised by the affirmation of a proposition, but in the biblical sense of emeth. In Pannenberg's (1971, p. 3) words, this Hebrew term for truth means "the reliability, the unshakable dependability, of a thing or word, and thus the faithfulness of persons." To be true, in this sense (so different from Western conceptions of truth as aletheia, correspondence, practical usefulness or justification), is to be worthy of trust. And this cannot be discovered by means of rational argumentation or intellectual insight, because what can be considered emeth is not a principle of intelligibility, immutable, identical to itself and beyond the contingent flux of experience and history. On the contrary, it needs to be discovered once and again in and through contingent historical experience. The reliability and stability of a person or a thing cannot be secured once and for all but is permanently open to be tested in future encounters. However, past experiences offer reasons for trusting. "Consider the past generations and see-says the author of the Ecclesiasticus - was anyone who trusted the Lord ever disappointed?" (Ecclus 2: 10). Accordingly, "the truth of the God of Israel did not disclose itself in its fullness to the logos of cogitative comprehension, as did the Greek aletheia, but only when met with trust in God's faithfulness" (Pannenberg 1971, p. 6).

Can that which is presupposed, in the sense here explored, be in this way trusted? In a certain way it can because, as we saw, our trust in absolute presuppositions is implicit in our forms of acting and thinking. It is basic, primitive and presumably beyond any possibility of being defrauded. But the security proper to primitive trust depends on the steadiness of the entire constellation of presuppositions, which however is historical and thus in permanent transformation and eventually it will decay. This sense of contingency, we said before, generates a feeling of fundamental uneasiness in the contemporary consciousness of the tacit dimension. Theistic faith, as a means of 
contrast, confronts fideistic trust with the absolute reliability of God. This confrontation not only puts the background in relation with that which transcends it but also questions it regarding the possibility of its own historical steadiness.

In this sense, theistic faith, as a radical, trusting openness towards transcendence, can still interpellate us today. Confronted by faith, our contemporary sense of living always working from within a particular historical background is called to respond to the question of whether the historicity of our human predicament needs, as its condition of possibility, the absolute trust that can be placed only in God.

Open Access This article is distributed under the terms of the Creative Commons Attribution 4.0 International License (http://creativecommons.org/licenses/by/4.0/), which permits unrestricted use, distribution, and reproduction in any medium, provided you give appropriate credit to the original author(s) and the source, provide a link to the Creative Commons license, and indicate if changes were made.

\section{References}

Audi, R. (2011). Rationality and religious commitment. Oxford: Oxford University Press.

Cardona, C. (2011). ¿Es Wittgenstein un Fundacionalista? Ideas y Valores, 60(146), 73-95.

Clouser, R. (2013). The myth of religious neutrality. an essay on the hidden role of religious belief in theories. Notre Dame, Indiana: University of Notre Dame Press.

Collingwood, R. G. (2014). An essay on metaphysics. Mansfield Centre: Martino Publishing.

Cottingham, J. (2003). On the meaning of life. New York: Routledge.

Dreyfus, H. (1995). Being-in-the-World. A commentary on Heidegger's Being and Time, division I. Cambridge, M; London: MIT Press.

Dreyfus, H., \& Charles, T. (2015). Retrieving realism. Harvard University Press.

Gadamer, H. G. (1990 [1960]) Wahrheit und Methode. Tübingen: J. C. B. Mohr. English edition Truth and Method. Trans. J. Weinsheimer and D. Marshall. London, New York: Continuum, 2004.

Gómez Rincon, C. M. (2017). Historicidad, realismo y verdad. Principia: An International Journal of Epistemology, 21(1), 77-98.

Habermas, J. (2003). Realism after the Linguistic Turn. In Truth and Justification. Cambridge, Massachusetts: MIT Press.

Heidegger, M. (2001 [1927]) Sein und Zeit. Tübingen: Max Niemeyer Verlag. English edition: Being and Time. Trans. John Macquarrie and Edward Robinson. Oxford: Blackwell. (SZ)

Hick, J. (2004). An interpretation of religion: human responses to the transcendent. Second edition. New Haven and London: Yale University Press.

Kennick, W. (1955). Metaphysical presuppositions. The Journal of Philosophy, 52(25), 769-780.

Malcolm, N. (1992). The groundlessness of belief. In D. Geivett \& B. Sweetman (Eds.), Contemporary perspectives on religious epistemology (pp. 92-103). Oxford: Oxford University Press.

Moyal-Sharrock, D. (2004). Understanding Wittgenstein's on Certainty. Basingstoke: Palgrave Macmillan.

Mulligan, K. (2006). Certainty, soil and sediment. In M. Textor (Ed.), The Austrian Contribution to Analitic Philosophy (pp. 89-129). London: Routledge.

Ortega y Gasset, J. (1977 [1936]). “Creer y Pensar”. In Ideas y Creencias. Madrid: Alianza.

Pannenberg, W. (1971). What is truth? In Basic Questions in Theology. Collected Essays Vol. II. Fortress Press.

Pascal, B. (1909). Thoughts. Harvard Classics.

Phillips, D. Z. (1993). Religious beliefs and language-games. In Wittgenstein and Religion (pp. 56-78). New York: St. Martin's Press.

Phillips, D. Z. (2005). Wittgenstein's On Certainty: the case of the missing propositions. In D. MoyalSharrock \& W. H. Brenner (Eds.), Readings of Wittgenstein's On Certainty (pp. 16-29). Hampshire and N.Y: Palgrave Macmillan.

Polanyi, M. (2009). The Tacit Dimension. Chicago and London: Chicago University Press.

Rilke, R. M. (2008). Das Stunden-Buch. Echo Library.

Searle, J. (1995). The construction of social reality. New York: The Free Press.

Stroll, A. (1994). Moore and Wittgenstein on Certainty. Oxford: Oxford University Press. 
Taylor, C. (1993). Engaged agency and background in Heidegger. In C. Guignon (Ed.), The Cambridge Companion to Heidegger (pp. 317-336). Cambridge University Press.

Wittgenstein, L. (1969) On Certainty. G.E.M. Ascombe and G.H. von Wright (eds). Trans. D. Paul and G.E.M. Ascombe. Oxford: Basil Blackwell. (OC).

Publisher's Note Springer Nature remains neutral with regard to jurisdictional claims in published maps and institutional affiliations. 